\title{
Marina D'Agati
}

University of Torino, Italy

\section{"I Feel Like I'm Going to Win": Superstition in Gambling}

DOI: https://doi.org/10.18778/1733-8077.10.2.05

Abstract Drawing on in-depth interviews with recreational gamblers ( $N=67$ ), the paper focuses on superstitious beliefs and practices used by players of various games to influence or control outcomes. The study was conducted in the spirit of the interpretative approach formed by folklorist Alain Dundes (1961). Results suggested that superstition, in a variety of forms - signs, magic, conversion - was clearly an accepted part of gambling for most respondents. Although more pronounced in games of chance, superstition appeared to be more significant in the experience of interviewees who played skill games, creating "illusion of control." Future research on the link between superstition and religion, and on the role of social networks in fostering and developing superstition-related knowledge is warranted.

Keywords Gambling Behavior; Gambling Beliefs; Magic; Personal Luck; Superstition

\section{Conceptual Background}

Sestri Ponente (Genoa, Italy), September, 2005: the champagne bottle used for Costa Concordia christening ceremony fails to smash when it is thrown against the hull.

Marina D'Agati is a researcher in Sociology at the Department of Cultures, Politics, and Society at the University of Torino, Italy. Her current research interests include: superstitious beliefs and behaviors, gambling behavior, the processes of socialization (with a particular interest in the dynamics within schools)

email address: marina.dagati@unito.it
Isola del Giglio (Grosseto, Italy), seven years later January, 2012: the cruise ship Costa Concordia hits rocks off the Italian Tuscan coast and partially sinks. It is Friday the $13^{\text {th }}$, on the centenary of the Titanic sinking.

This recent disaster exemplifies the use in everyday life of a class of beliefs and behavior that migh well be labeled "superstition": the ceremonial champagne bottle does not break, Friday the $13^{\text {th }}$.

There is controversy concerning the exact criteria that should be used to determine whether a belief or practice is superstitious or not. As a result of the confusion around this concept, the term "superstition" encompasses a multitude of meanings and interpretations. Researchers, in turn, have characterized superstition as irrational thinking (Kramer and Block 2008), a ritual which usually takes place in contexts of uncertainty (Malinowski 1955), a belief that relies on a mistaken causal link between two independent events (Foster and Kokko 2009), a "pseudo-religion" (Pihlström 2007), a belief inconsistent with scientific knowledge and self-oriented (Stanke 2004), a paranormal belief or behavior (Hergovich, Schott, and Arendasy 2005; Aarnio 2007), a confusion of core knowledge about physical, psychological, and biological phenomena (Lindeman and Aarnio 2007), a "half-belief" (Campbell 1996).

Very often, the definition of superstition is omitted or substituted with examples of such beliefs and behavior (Žeželj et al. 2009). In this lack of conceptual clarity, the borderline between superstition, the paranormal, magic, witchcraft, or even religion is ambiguous and vague (Delacroix and Guillard 2008).

This study is based on the work of folklorist Alan Dundes (1961) who proposes a definition of superstition in term of grammatical conditions and results. The distinction between "generalized belief" and "superstition" relies on the "Condition-Result" structure of superstition. According to Dundes, "superstitions are traditional expressions of one or more conditions and one or more results with some of the condition signs and others causes" (1961:28). Generalized belief does not have this basic structure, but normally states a matter in the form of direct and general statement. So, never open an umbrella in a house, or you'll have bad luck has a "Condition-Result" structure and is superstition; on the contrary, the porpoise will push a drowned body to shore is not superstition.
Analysis of the relationship between conditions and results enabled Dundes to classify superstition in three main categories

The first is omen, significant coincidence or synchronicity. Dundes called it sign. Such superstition is generally made up of a single condition and a single result, often serving as the basis of prediction. Thus, in Western culture, Friday the $13^{\text {th }}$ is bad luck or if one finds a penny, it is an auspice of good luck. Under this category Dundes found two kinds of superstition: non-human signs - consisting of celestial, animal, and plant indicators, for example, a red moon means death by pestilence, and accidental or coincidental signs of human activity, for instance, if the champagne bottle does not break, it is an omen of bad luck, or if one's palms itch, money is coming. Signs are purely accidental or coincidental and man is passive - when a black cat crosses your path, there is nothing you can do to avoid that happening. People may read such portents; moreover, no activity is required in interpreting either the shooting star or whippoorwill's call as a sign of death.

Unlike signs, magic is causal. Dundes argues that this second category of superstition is concerned with manipulating the future, not with predicting it. Instead of foretelling death and good/bad luck, one can, using magic, bring death or good/bad luck. Thus, magic aims to produce desired results: for example, when launched, a ship is traditionally christened by breaking a bottle of champagne against its bow. Human activity is intentional and man is active with regard to magic. Since human activity is intention$\mathrm{al}$, it is also avoidable: for instance, one can avoid seven years of bad luck by not breaking a mirror 
Therefore, unlike signs based only on belief, magic superstition requires both belief and practice. Lastly, magic frequently makes use of rituals, as seen by looking at cures and divinations.

Dundes named conversion the third type of superstition - it is a hybrid category in which signs are put into practice, that is, they are "converted." Here, the individual's action is required. Friday the 13th is supposed to be a day ("Condition") of bad luck that may be passively observed. One's action to prevent the outcome presaged by the sign Friday the 13th is "conversion": maybe, staying at home or not travelling ("Result"). Similarly, some people consider finding a penny a sign of good luck. In a sense, this is a call to action, to shape the future rather than just let things happen - thus, one could purchase a lottery ticket and hit the jackpot.

Thus, for Dundes, superstition is a macro-concept encompassing a complex set of phenomena, including magic. In other words, just like conversion or signs, magic involves some of the possible manifestations of superstitions. In this article, I will try to understand whether and how Dundes' approach can help researchers investigate the role of superstition in gambling behavior and practice.

\section{Focus and Objectives}

Superstition related to gambling behavior receives considerable attention in several fields; sociologists, however, have not addressed it much. Henslin's classical article, "Craps and Magic" (1967), was one of the first sociological studies of superstitious phenomena. He observed that crapshooters often believed they were able to control the outcome of each throw of the dice. For example, they might link the force employed when throwing the dice (hard or soft) with the number obtained (large or low). So, when they needed low numbers, they rolled the dice gently; when they needed large numbers, they cast them in an energetic fashion.

The purpose of this paper is to examine in depth the role of superstition in the creation, maintenance, and legitimization of gambling behavior. It deals with recreational gamblers, those for whom gambling is a leisure time pursuit, thereby excluding two types of gamblers, that is, the professional and the compulsive. The focus on regular gamblers is for two reasons.

First, because the ways superstition affects what constitutes "normal" or low-risk gambling behavior has not yet been fully explored. In addition, qualitative accounts of the superstitious and magical beliefs, values, practices influencing or directing gaming decisions are lacking. Further work on these issues is central to understanding why some gamblers have a greater perception of control and believe in their ability to alter fate; why for some individuals superstition may have a robust influence on gaming decisions, while for others less so; why, more broadly, superstition does not decline in modern society. Furthermore, these issues become sociologically interesting from the perspective of explaining superstition in a rational, logical way.

Second, because in Italy research on gambling behavior has been surprisingly scarce until now, though interest in it is growing (D'Agati 2004; 2005)
This lack of interest is surprising given that in the early $16^{\text {th }}$ century games such as the Lotto were seemingly widely practiced in Genoa.

There are three objectives of this study. The first is to provide descriptive information on superstition - as defined by Dundes, that is, a complex phenomenon which includes signs, magic, and conversions - and its effectiveness in gambling from the viewpoint of players. Relevant questions include: Which of Dundes' categories are most common in gambling behavior? What is the nature of the magic in the gambling process? What exactly are signs and conversions?

The second objective is to examine the circumstances in which superstition will be most pronounced. That is, when is a gambler more likely to call upon superstitious practices or beliefs? Is it when he/she is unfamiliar with the rules of a given game? Or in situations when his/her perception of control wavers? Or, is it when the outcome of a game/bet is perceived by the gambler as crucial or decisive? By definition, gambling involves risking something of value on the unknown outcome of some future event. ${ }^{1}$ However, the degree of uncertainty in games varies. Since gambling is a complex phenomenon, "chance-skill" analytical distinction, first raised by Caillois

Although there is much debate on how to define, assess, and 2001; Weiss, Demski, and Backen 2011), for the purposes of this paper, the term gambling is confined to its conventional meaning. The definition adopted here is that of sociologist Edward Devereux (1968) who referred to gambling as an "activity in which the parties involved, who are known as bettors or players, voluntarily engage to make the transfer of money or something else of value among themselves contingent upon the outmeans risking something of value on the unknown outcome of some future event. This definition covers all forms of gambling, whether undertaken privately or offered commercially.
(1961), may provide a conceptual framework for categorizing different gambling activities. Therefore, it is useful to distinguish between "games of chance" and "games involving some skill" (or both skill and luck). The former typically refers to gambling in which winning is purely a matter of chance. From this point of view, in games of pure chance, the outcome is unpredictable as it is beyond the gambler's control - consequently, these activities do not require skill or knowledge, and the underlying events on which gamblers bet are both random and independent. Examples of games of pure chance include: roulette, slot machines, lotteries, bingo, and others. Conversely, the latter refers to activities involving different degrees of skill and luck. Here, the success of gamblers may depend on their knowledge, strategies, and decisions during play. Games involving both luck and skill include, for example, horse race and sports betting. From this perspective, in soccer matches gamblers can make intelligent guesses and bet on a particular team based on previous statistics and knowledge of the current quality of the team. So, those with more knowledge and skill may have an objective advantage over other gamblers.

So, in view of all this and considering the complexity of gambling, can superstition be considered a response to situations of high uncertainty? In other words, how much more likely is a gambler to call upon superstitious beliefs or practices when the outcome of a bet is subject to chance or luck rather than controllable forces (such as skill, ability, preparation, etc.)? It is assumed here that the structural characteristics of games (i.e., whether they are games of chance or games of skill) may influence superstitious belief and behavior to some degree, but not 
completely. Although it might be expected that superstition is more pronounced in games of chance, there is no reason to assume that the belief in and practice of superstition declined with advancing certainty, for example, in games involving skill.

Contrary to the uncertainty hypothesis introduced by anthropologist Malinowski, I also consider that, no matter whether in games of chance or of skill, gamblers resort to superstition because they believe that the outcome is determined by controllable forces. Related to this is the perception of randomness - chance and skill may differ according to whether they are perceived from the inside, subjectively by a gambler, or from the outside, objectively by an observer.

I am also interested in understanding at what stage in a bet a gambler is more likely to call upon superstitious beliefs and/or practices. It is at the start, that is, before the odds are defined, or after placing the bet, perhaps to justify the event of defeat to others? Or else, is it while actually placing the bet (as an act of support), when nothing is known yet about the outcome of the wager?

Finally, the third objective of this study is to focus on the dynamics and processes by which superstitions become part of a game, influencing it. In other words, how might a sign, for example, affect an individual's bet? This article hypothesizes that the concepts of conversion and magic, as defined by Dundes, help interpret how people incorporate superstitions and other luck-related strategies into their gambling ventures. Specifically, both concepts suggest an idea of superstition that is causal rather than random, in which belief and practice overlap and influence each other mutually.

\section{Methodology}

\section{Design}

This research is qualitative in design, using mainly individual in-depth, face-to-face, interviews. Narrative accounts were selected as the mode of data collection, the aim of the study being detailed exploration of experience, behavior, attitudes of gamblers, and evaluation of the factors affecting them. Also, interviews were supplemented with occasional visits to betting shops and casinos as observer.

\section{Participants}

Sixty-seven gamblers ( 40 men, 27 women) participated in the interview process. Their age ranged from 18 to 76 years. At the time, all interviewees lived in or around the Turin area; one was in Naples, two in Rome.

Any study of gambling behavior is notoriously fraught with a multiplicity of methodological difficulties. Firstly, although many people admitted gambling in one form or another, very few considered themselves "gamblers" at all. Some did not consider buying lottery tickets or betting on a horse as gambling. Secondly, people are often reluctant to own up to strangers about their gambling habits. So, it is hard to find individuals willing to talk about their gambling. This explains why the snowball sampling approach was adopted for recruiting: interviewed subjects gave researcher referrals of other potential respondents. Thus, the sample was specifically designed to achieve range and diversity, and was not intended to be representative of the wider gambling population. Selected gamblers had to meet the following criteria:

a. not to have had previous problems with gambling;

b. play games of chance (Lotto, ${ }^{2}$ SuperEnalotto, ${ }^{3}$ Roulette, national lotteries and instant lotteries, Bingo, etc.) or games of skill (Totocalcio, ${ }^{4}$ sport betting or horse race betting);

c. gamble regularly. ${ }^{5}$ The aim was to select only people who were significantly engaged in gambling.

The Lotto is a very ancient game in which five distinct nument Italian cities, three times a week (Tuesday-Thursday-Saturday). Gamblers can place several types of bets: estratto, ambo, terno, quaterna, cinquina. Betting two numbers is called ambo and pays off at 250 times your original bet. Betting three numbers is terno; four, quaterna, and five, cinquina. These pay off, respectively: 4,250 times, 80,000 times, and one million times whatever you bet.

The SuperEnalotto is a popular Italian lottery draw game that was launched in 1997. It is played three times a week on Tuesday, Thursday, and Saturday night and offers huge jacka choice of $1-90$ and they must match all six of these numbers to

列 1946 and is dina (betting card), must predict the outceme of 14 football matches. The Totocalcio was an immediate success and soon came to symbolize Italy's "economic miracle," in a country, which was beginning to have hope and believe in its ability to change. Today, Totocalcio is on the decline on account of competition from other similar betting games that are considered provides more freedom and is not restricted to making forecasts on a pre-defined list of 14 matches. Any adult can build his or her own betting card from the matches that interest them the most (which may be one or several) and select the forecasts they prefer.

For Roulette, "regular" meant at least once a month. For the other games, at least once or twice a week.
For the sake of anonymity, all interviewees were given pseudonyms.

\section{Procedure}

Most of the data used for this article come from interviews $(\mathrm{N}=54)$ collected between February 2003 and May 2004. Further interviews ( $\mathrm{N}=13)$, conducted in 2012-2013, were also used. Gamblers were interviewed at a location of their choosing (their home, the researcher's office, a local coffee shop etc.). Four subjects preferred telephone contact; eleven declined to be interviewed after the study was explained to them.

Interviews were semi-structured, generally lasting 45 to 90 minutes. Questions were open-ended to allow participants to direct the conversation. The main focus of each interview was the participants account of their gambling experience and attitude. Interviewees were asked to describe the different strategies they used and to provide examples of each. In several cases, some players were invited to make a prediction, for example, filling out a coupon for Totocalcio, sport and horse race betting, or Lotto. They were also involved in discussing the experience of winning (through anecdotes, major episodes, etc.) and the emotions felt when losing.

\section{Analysi}

Interviews were fully recorded and transcribed verbatim. Detailed inspection of the texts was used for identifying recurring patterns. Transcripts were then submitted to content analysis by the interpretative approach proposed by Dundes (1961). Results 
hereunder, topic by topic, start with signs, followed by magic, conversion, and content characteristics. Each section contains direct quotations. All quoted extracts include information on the gambler's pseudonym, game/games most practiced, and age.

\section{Discussion}

\section{Signs or Accidental Superstition}

The first type of superstition emerging from the analysis of the interviews conducted presents strong points of contact with Dundes' concept of "signs." This form of superstition is generally accidental: premonitions, hunches, indicators of good or bad luck, in some cases, looked for or pursued, but not intentionally produced by the gambler. For example, looking for a four-leaved clover may be a very long activity; finding it, however, is a completely random event. One important aspect of signs is, moreover, that they may constitute, as we will see in the next paragraph, the basis for formulating forecasts.

Respondents' experience provided considerable evidence of superstitious omens and portents alluding to a narrow distinction - autobiographic and non-autobiographic signs. ${ }^{6}$ The former are "inside" portents and omens directly related to gamblers' lives or with some sort of special significance to them; non-autobiographic signs, on the other hand, are "external" and refer to events not directly related to the gamblers' life, but which are taken over by gamblers.
Our discussion begins with autobiographic signs, for which the analysis of the interviews provides a wealth of information. Autobiographic signs mentioned include, first of all, superstitious belief in the "power" of dates, such as family birthdays, anniversaries, recurrences, or certain numbers "assigned" by someone. This kind of conviction is frequent especially in chance-related games which involve making forecasts on the extraction of numbers, such as Lotto or Roulette, or numbers-based games in general, such as Bingo. As the interview extracts show, some gamblers assign a premonitory significance to circumstances and events of their own lives, such as births, weddings, and anniversaries. In other words, they consider these events (which are not always random, as in the case of wedding dates) as signs of good or bad luck.

I've got "my" numbers...: 4, which is my birthday and 18 , which is my granddaughter's birthday [Angelica, Roulette/SuperEnalotto, age 62]

7 and 11 are "my" numbers. ... Why I liked them? The numbers of my basketball T-shirt were 7 and 11, so... [Marco, Lotto, age 43]

When I buy a [Bingo] card, I immediately look to see if it has any lucky numbers. For example, 15, which is the day of my wedding anniversary, or 17 , which has always been lucky for me when I'm playing. Or, even 6, the day my husband was born and 20, which is my birthday. If the card has none of these numbers, or no numbers that are simila to them (I don't know, 51, say, which is the opposite of 15), I know, it's not going to be a good round for me [Stefania, Bingo/Lotto/Roulette, age 55]
Therefore, as suggested by the stories of the gamblers, the process of building a reliable gambling sign runs along biographical lines (their own or a loved-one's birthday, a basketball shirt number, etc.). A sign is considered reliable if it somehow links to the person's existence or aspects of it. It is not uncommon, as in the extracts below, for repetition to be the guarantee of the "reliability" of a portent in the eyes of a gambler.

12 is a recurring number in my life because on the $12^{\text {th }}$ I met my two husbands...; because my son was born on the $12^{\text {th }}$, and his bed number in hospital was 12 [Angelica, Roulette/SuperEnalotto, age 62]

When you wake up, as I have done, for three nights...at the same time for three nights in a row...you take it as a sign... You see it as a positive sign [Vittorio, Lotto, age 44]

Adopting autobiographic signs is frequent, as I said, especially in chance-related games; although to a lesser extent, they are also found in skills-based games. Of my interviewees, three horse race bettors and four respondents keen on Totocalcio and sport betting mentioned autobiographic signs. Those refer mostly to intuition, empathy, or attachment to a football club, taken as "prophetic signs." Typical statements in this regard are: "I've always been guided by my instinct" [Loredana, horse race betting, age 56], "[i]t's bad luck to bet on your favorite team's defeat" [Enrico, Totocalcio, age 42], "[y]ou should never bet on your own team. It's bad luck" [Mara, Totocalcio/sport betting, age 39].
In spite of this, most respondents betting on games of skill were especially critical of what they perceived as lack of commitment and poor teaching skills of some gamblers. The following extract reflects this perspective:

[y]ears and years ago there was [a horse named] "Irma Ve" and I was in love with a girl named Irma, but I've never played Irma Ve because.. my woman was good, but the horse wasn't! The real punters don't pick a horse at random because they like the name... There are many factors to be considered when betting on a horse...the odds [of a horse winning], information about the fitness level of the horses, performance in previous races and pedigree, track conditions, some lucky rumors... [Giuseppe, horse race betting, age 44]

Precognitive dreams also featured in interviews as a sign that some gamblers considered to be harbingers of luck. More subtly, dreams that respondents described can be classified into two categories

The first contains dreams in which they claimed to have seen numbers: "[n]umbers were strong and clear, and I played them" [Luca, Lotto, age 68], "[s]ometimes I dream some numbers, for example, a bus number" [Ambrogio, Lotto, age 38]. Sometimes one or more characters in the dream disclosed "winning" numbers: "I once dreamt my grand ma who told me to write numbers on a piece of paper" [Tiziana, Lotto/SuperEnalotto, age 47], "[i]n that dream an unknown person gave me his mobile number. I saw it...it was divided into several parts, in numbers of two digits" [Amanda, Lotto, age 33]. 
The second category of dreams was more common among respondents and constituted very strong triggers to gamble. It contained images and actions of different individuals they knew, including family members, friends, or neighbors: "[w]hen I dream about my grandparents, I always play some numbers on the Lotto" [Marzia, Lotto, age 46]. In these types of dreams, deceased loved ones often return to visit those they have left behind and give them advice.

Data show that autobiographic signs can also be objects. Many of the gamblers interviewed had their own specific lucky charms, including pens, talismans, or even particular garments which go everywhere with them. Nonetheless, lucky charms do not all have the same value. As Antonello notes, "[l]ucky charms must be gifted to you if you want them to work" [Lotto/Totocalcio, age 46]. From his perspective, Antonello's anti-jinx card made him feel lucky, it having been gifted to him by a friend.

Another commonly mentioned sign - which in this case is not only autobiographic in nature but often is also non-autobiographic - includes different types of distressing and tragic events. These were seen as synchronicities or coincidences which "mean something" rather than misfortune. It emerged as a significant theme in gamblers' experience, especially for those who played Lotto. For example, disgrace, accidents, or the death of loved ones (relatives, friends, acquaintances), tragedies (earthquakes, the 9/11 attacks), the passing of a celebrity or someone unknown to them. As we will see in the next paragraph, the conversion process gives these events a different, new - paradoxically - positive and playful meaning.
Staying with non-autobiographic signs, hence with events unrelated to the gambler's life, the experience of extraordinary situations that are "strange," in some ways surprising and "interpreted" as portents, is recurrent in the stories of the gamblers. For example, the striking repetition of some numbers, a vehicle overtaking another, or seeing a car's plate numbers or signboards, et cetera.

If you see a coffee spoon fall, it means you're about to have good luck. [Annalisa, Lotto/Gratta e Vinci/ SuperEnalotto, age 34]

Sometimes there is a strange coincidence and you win. I remember that once a car overtook me and its plate number was $18881 . .$. It was a small car, maybe it was a Fiat $126 \ldots$ I was driving very slowly and it was a crazy overtaking maneuver... I loved it [that plate number]... [Stefano, Lotto, age 44]

Furthermore, some respondents believed past random events to contain information on future realization. From this point of view, they thought that the delay was a sign that "means something." In games of chance, it might consist in the numbers of draws after which a particular number was due to appear. When playing the Lotto, some interviewees tended to expect that a certain number (or a combination of numbers) would be more likely to come up if it had not been drawn for a long time; similarly, when playing Roulette, others tended to expect that a black number would be due after a sequence of red numbers. In games of skill, horses and football teams can be erroneously perceived in a similar way. In Totocalcio or sport betting, some respondents often perceived a series of losses by a team as strong evidence of impending success. This illusory belief has been dubbed "gambler's fallacy" (Tversky and Kahneman 1971), as shown hereunder, it is a tendency to believe that a streak of events is likely to end.?

[He comments while filling out a football pool coupon] so...Perugia-Brescia... Brescia...is slightly stronger than Perugia; but Perugia hasn't yet won a match, and for this reason, I would bet on Perugia winning. [Paolo, Totocalcio, age 49]

Look at the latest Lotto draw results. Analyze carefully the various draws, and you can see what I call "coincidences." ... For example, let's start from the first wheel: [that of the city of] Bari. So, in [the draw of] Bari there aren't numbers ending with zero, or sets of numbers with the same last digit, $^{8}$ or numbers with two identical digits... So, this is, in my opinion, a draw that needs to be considered. On the basis of my learning and experience, I realize that the lack of coincidences lasts up to three times... Then, the fourth time one of those numbers comes up. [Battista, Lotto, age 76]

There was also evidence of interviewees' belief in "hot outcome." This is the opposite of gambler's fallacy and refers to expectation of positive results in random sequence. ${ }^{10}$ For example, some Roulette

The "gambler's fallacy" is a belief in negative autocorrelation of a non-autocorrelated random sequence of outcomes like coin flips (Sundali and Croson 2006:1). It is also known as the "Monte Carlo fallacy" (because its most famous example happened in a Monte Carlo casino in 1913)

${ }^{8}$ For example, 15-25-35.

${ }^{9}$ For instance, 11-22-33.

10 "Hot outcome" is an (incorrect) belief in positive autocorrelation of a non-autocorrelated random sequence (Sundali and Croson 2006:2 gamblers believed that a streak of blacks from the wheel would continue because black was hot. Some Lotto respondents paid attention to the frequency with which a particular number had come up in the past, as in the following comment:

[m]y father had a big influence on me [my gambling]...he suggested recently that I should pick frequent numbers. ... Generally, [when I go to the casinol, in the first fifteen to twenty minutes, I take a look at the different Roulette tables... I look for hot numbers and I play them. [Edoardo, Roulette, age 25]

\section{How Gamblers Incorporate Superstitions into}

\section{Their Gambling Ventures: Non-Random}

\section{Superstition}

In this paragraph, I will consider the ways in which superstition becomes a concrete part of the process of gambling. The focus of my analysis shifts therefore from superstitious beliefs (which were identified as signs in the previous paragraph) to superstitious practices. Specifically, I will show how Dundes' concepts of "conversion" and "magic" - the former concerning the area of forecasting and the latter the area of manipulating the future - can help researchers focus on the process by which gamblers translate their superstitious beliefs into the act of gambling, leading to definition of forecasts or predictions.

\section{Conversion: The Translation of Signs into Practice}

The concrete use made of signs by the gamblers interviewed is reminiscent of another type of superstition, which Dundes refers to as "conversion." In 
fact, "conversion" is closely related to the concept of signs and it is their translation into practice. Nearly all respondents playing games of chance mentioned conversion.

It is not infrequent, as in the examples that follow, for conversion of a sign to be a fairly quick and simple operation, requiring no other effort than paying attention to all surroundings, both outer and inner, and intuitively taking advantage of synchronistic and coincidental events (signs) occurring in everyday life.

I always play...number 74, my mother's age when she died, and 28, the day she died. [Diana, Lotto, age 62]

Last week, I went to the Christmas market at Montreux. So... I picked 20, that is the day I went [to Montreux]...and number 6, which was the departure time. ... Yes, I was inspired by that trip [Aldo, Lotto/SuperEnalotto, age 34]

There are dates in all of our lives that are luckier than others. They say that one of the best days in our lives is when we get married. That's why when Giuseppe [my husband] and I got married, we didn't ask for money or appliances or holidays...but the equivalent in Gratta e Vinci ${ }^{11}$ because we love them! So, at the end of our wedding reception we had over 800 cards to scratch! [Rossella, Gratta e Vinci, age 37]

In the first example, Diana plays Lotto using numerology related to her mother's death. She "converts,"

${ }^{11}$ Introduced to Italy in 1994, Gratta e Vinci is an instant card lottery system with a hidden foil-covered section. The silver or gold foil is scratched away to reveal the winning combination
(usually symbols or numbers) and the value of the cash prize. that is, translates, into odds the signs considered to predict good luck: "my mother's age," the "day she died." The second Lotto player draws inspiration from a trip taken, using numbers corresponding to the date and time of departure. In the third case, "wedding days" are considered portents of good luck. The consequent act of conversion consists in putting into practice what is considered an indicator of good luck by making a somewhat original request - to receive instant lottery tickets as a wedding gifts.

Also surprising or apparently "strange" signs (especially non autobiographical, as we saw in the previous paragraph) become a great source of inspiration for conversion superstition, for instance, the striking repetition of some numbers, signboards, or car's plate numbers, et cetera. Such superstitions were very popular among those who engaged in Lotto and in general in games of chance; however, some of those who were keen on games of skill seemed also to succumb to the charm of these beliefs.

It was two years ago... I won two thousand five hundred euro. I was in my office filing some documents...and it occurred to me to see two numbers. Then, I saw them again, by chance, on a piece of paper. Then, a colleague called me to say, "Please, could you go to the post office to pick up a letter?" Okay, I went to pick up the letter. I take a look at the envelope: the same numbers again. ... When I saw those numbers, I felt a shiver down my back, and then I thought that I had to play... [Vittorio Lotto, age 44]

ast month I saw a car in a movie on TV. It attracted me because it was an antique model and I saw the registration number. I took note of it; I played the numbers and won. [Giovanna, horse race betting, age 47]

A colleague and I stopped at the entrance of the church to wait for the hearse carrying our boss to arrive....and then, when it did, my colleague said to me "Let's take note of the plate number... We'll bet [the plate number] on the Lotto." And so, I first started playing Lotto systematically. It has me gripped. My colleague gave me the input. as I had never played the Lotto before in my life... [Antonello, Lotto/Totocalcio, age 47]

In the last extract, the gambler described a particularly poignant episode in which a daily event took on a whole new meaning. The number plate of the hearse bearing his deceased boss - a negative event - is perceived by Antonello's colleague as being a favorable circumstance, that is, a sign pointing to future good luck. This story allows us to introduce another form of conversion, which draws inspiration from inauspicious events which may either concern the gambler's close network (including strong relationships with family-members, friends, and even acquaintances) or a wider, less family-related context, such as the international scene or television. "Even in what is called misfortune, there is good fortune to be discovered" [Marzia, Lotto, age 47], observes this gambler. Thus, bereavements and exceptional or tragic episodes are submitted to a process of conversion into numbers to bet on. It emerged as a significant theme in gamblers' experience, especially for those who played Lotto or Roulette as in the following comments: [f]ifteen years ago a friend of my mum and her family died in a car crash. My mum and I played the numbers [associated with this accident] and they all came up. We played the numbers of the day and the month of the accident, the members of the family who had died. That week we got lucky. All the numbers came up.... I think there may be something magical, which makes numbers come up, because it's strange that these numbers [those associated to tragic events] came up. [Marzia, Lotto, age 47]

I picked the numbers for the $9 / 11$ attack...[but I said to myself], “Oh my God, how shameful! It's ridiculous." [Diana, Lotto, age 62

[Many people bet on] the numbers of Marco Pan$\operatorname{tani}^{\prime} \mathrm{s}^{12} \ldots$ or Alberto Sordi's death. All these numbers were drawn! ... [You have to pick numbers corresponding to] the day they died [and] their age. [Viviana, Lotto, age 44]

Beliefs such as "gambler's fallacy" and "hot outcome" (see Signs above) are often at the origin of many conversions, as mentioned. Some Lotto players track past draws in order to find meaningful signs from their point of view; then, they adjust their choices to the period in which a certain number has not been drawn, or tend to favor numbers drawn in several consecutive weeks, that is, "on streak." Similarly, football punters sometimes think that a team that has lost, say, two matches in a row may be "due" for a win.

${ }^{12}$ Marco Pantani, nicknamed "The Pirate," was an Italia road-racing cyclist. Alberto Sordi was one of the most popular Italian movie stars. 
Sometimes, I buy the newspaper and if I see that a number, say 17 , has not been drawn in the past fifteen draws or more, I feel I must play it. I play it with other numbers. For example, last week I played the combination 17 and 6, and it came up. [Stefano, Lotto, age 40]

[He speaks while filling out a football pools coupon] So, Triestina-Atalanta... Well, the Atalanta comes from two consecutive losses, last Thursday lost at home 1-5... Well, I think Sunday Atalanta will not lose...I'm expecting a score like 1-1. [Salvo, Totocalcio/sport betting, age 20]

However, translation of a sign into a forecast is not always as quick and simple as the above cases seem to suggest. In many gamblers' experience signs, no matter whether autobiographic or non-autobiographic, usually required a good deal of interpretation. Some gamblers stated clearly that "hard work" combined with experience of play made the difference:

[m]y aunt...recommended to me [play numbers] using the first letter of the first name or last name. For example, a man called Charles has to play numbers in [the draw of the city of] Cagliari...or if you are Livio [and] there isn't a draw which begins with the letter ' $\mathrm{L}$ ', [you have to take the initial of] your last name. If there is neither the initial of your first name nor the initial of your last name, [you have to take the first letter corresponding to the place] where you were born. If there isn't, [you have to take] the initial of the region, and so on. Or, [you have to play in the draw of the city] where you live. [Vittorio, Lotto, age 44]
Findings revealed that conversion also emerges as a result of dream interpretation. Behavior of that nature is mostly specific to Lotto gamblers. Half of them considered dreams as signs needing further understanding or analysis. Gamblers reported some sort of techniques for choosing lucky numbers. From this perspective, La Smorfia, ${ }^{13}$ the popular Neapolitan book, contains lists of numbers associated with hundreds of dreams and events.

Two days ago, I had a dream that my mom gave my husband a kiss... So, I played 47... Because [in La Smorfia] 47 is "the dead." ... It's my mom. Then [I played] 71 because [my mom] gave a kiss to my husband and I interpreted that her kiss would protect him...because my mom was very sweet when kissing him and according to La Smorfia...the number was 71 . Then, I played 4 because my mom came down the stairs and gave my husband a kiss and the stairs in La Smorfia are number 4. And then, I played 17 because [my mom] hugged [my husband] and the hug is 17. I've played in [the draw of the city of] Turin because [in the dream] the stairs reminded $\mathrm{me}$ of those in my mom's home. [Viviana, Lotto, age 44]

Using lucky charm gifts is another typical conversion reported by some respondents. Objectively, a lucky charm given by someone is different from buying lucky charms for yourself. Lucky charms given can be regarded as an accidental or coincidental sign experienced without active or concerted effort, that is he or she receives a gift, maybe unexpected. With charms bought, the lucky charm is the result of in-

${ }^{13}$ La Smorfia is a traditional Neapolitan book which assigns numerical values $1-90$ to an exhaustive list of things, including occurrences, concepts, and dreams. tentional action, that is, he or she deliberately buys a certain object for magic purposes. Consequently, using a good luck charm gift for gambling purposes is a conversion, a transformation of a sign (the gift); on the contrary, as we will see in the next paragraph, using a lucky charm bought by yourself is magic.

However, from a subjective viewpoint, some respondents believed that gifted lucky charms worked better than lucky charms which were not gifted. As it emerges in the following comment, Antonello felt more confident when using a card which he considered a sign of good luck because given to him by a friend: "[v]ery often I rub [the ticket played] on it..." [Antonello, Lotto/Totocalcio, age 46]

Conversion might be inaction to prevent the outcome presaged by the sign. For example, for Mara, Friday the $13^{\text {th }}$ was a bad day (sign) which would affect her game play; she converted the presumed omen simply by choosing not to gamble: "I never play on Friday the $13^{\text {th }}$ " [Mara, Totocalcio/sport betting, age 39]. The same can be said in the first of the two extracts that follow. Believing Wednesday to be an unlucky day, Antonello prefers to delay betting until a less inauspicious day.

The case in the second extract, however, is different: conversion consists in trying to benefit from the good luck pointed to by a sign. Annalisa (a gambler we met in the section on signs) considers seeing a coffee spoon fall as a portent of good luck, and thus, feels encouraged to bet.

Wednesday isn't a lucky day. That's what I've been told. I was born on Wednesday. That's why I never bet on Wednesdays. [Antonello, Lotto/Totocalcio, age 62]
Whenever I see a coffee spoon fall, I have to bet, on anything, Lotto, SuperEnalotto, or Gratta e Vinci, but I have to bet on something. [Annalisa Lotto/ Gratta e Vinci/SuperEnalotto, age 34]

In other cases, conversion appeared as a strategy in response to gambling loss. It was some kind of rationalization, a need for some respondents to somehow justify the failure of a gambling tactic in their own minds. They attempted to psychologically accept their own actions and emotionally "shift the blame" to anyone or anything other than themselves. From this perspective, some particular physiognomic signs and characteristics of hoodoos were associated with bad luck; some respondents might transform such accidental omens into magic by using them as a scapegoat for gambling losses.

We [my friend and I] stopped at a Roulette table where there was a croupier with the evil eye...we made two or three bets, but we didn't win; then my friend said: "Let's go away, this croupier is bringing us bad luck!” [Greta, Roulette, age 46]

Following an unsuccessful bet, the punter...links his lack of success to the presence of people believed to be suspect and untrustworthy: "Here there are too many with the evil eye, it's not possible to bet, that's enough!" [from field notes]

Magic: A Way to Manipulate or Control Gambling Outcomes

Another form of superstition throwing light onto the process by which gamblers translate their convictions into the act of gambling is "magic." 
Data show the existence of at least two types of magic - "ex-ante magic" and "ex-post magic."

"Ex-post magic" takes place after placing a wager on the game's outcome. It is an act of superstition, which works as "support" for one's bet. In this sense, it becomes an addendum to the bet rather than being the reason for it. It may follow number choices or forecasts of the outcome of sporting events or matches, that is, the winner of a horse race or to predict whether or not the favored team wins by $\mathrm{X}$ points.

Most of the "ex-post acts of magic" described by gamblers seem to link the belief in luck as a self-perceived personal quality to the two main laws of sympathetic magic (Frazer 1890). Although conceptually distinct, the laws of contagion and similarity tend to blend in. Extracts of the interview with Alessandro offer a clear understanding of this:

[i]f I buy a bet slip at the racetrack, I put it in my left rear pants pocket. If I win, I put the next slip there, but not for superstition. It's just a gesture... I try, but I'm not superstitious. [It's something you do] hoping things go well... [Alessandro, horse race betting/sport betting, age 42]

In attempting to influence the outcome of the race, Alessandro first transmitted his supposed "lucky" property (a portion of his person, his back ${ }^{14}$ ) to the ticket through brief physical contact (an instance of contagion); then, his personal luck transferred from the numbered ticket to the horse bearing the same number (the law of similarity). From this perspective, luck was perceived as an unconventional skill and the use of sympathetic magic occurred in the service of illusory control.

Note that even though Alessandro practiced magic he emphasized he did not believe in it very strongly. Magic was partially accepted by this horse bettor who distanced himself from his superstitious practice. "I'm not superstitious," he says repeatedly; but, he does not seem to be entirely sure as he adds, "[y]ou never know" because if he wins, he continues placing the bet slip in the left rear pocket of his trousers.

Thus, some respondents behaved as if luck was the ability they possessed, which could be transferred to an object central to the game (a horse, some numbers, a ticket, etc.) by mechanisms akin to sympathetic magic. Also, the use of inanimate objects, such as charms or amulets (not given to them by someone, but bought for themselves; see under Conversion), reported by gamblers can be understood in this way.

[Making me see a card that shows a list of some numbers of La Smorfia and a memorandum of how much money you could win playing Lotto] Here are numbers and their meanings. If you dream something, maybe...the Italian flag, you go there to see what number is associated with it, and maybe find it Italy is number 1.47 is "dead man"...90 is "fear." I use it, after playing Lotto, to see how much I can expect to win....as a lucky charm. [Marco, Lotto, age 43]

Respondents also reported following certain "liturgical" patterns or recommendations. For Diego
[Lotto, age 28], "[p]eople who tell their numbers will never win." Consequently, after selecting a number, he starts a sort of "propitiatory silence" according to which numbers must not be revealed.

Another "ex-post magic" respondents declared practice was that of the Roulette world. In their experience, frequently used acts take place when the Roulette wheel spins or the slot reels are coming to a stop. For example, it is common for some interviewees to naturally cross their fingers and hope that they get the winning numbers, change seats and position, if they are losing, or never watch the Roulette wheel as it spins.

In contrast, "ex-ante magic" is an act taking place before placing a bet on the game's outcome. It may consist of a form of influence a player can have over the outcome, both in games governed by a random selection process and in games of skill. Here, what matters in determining the outcome is ex-ante preparedness rather than ex-post luck. From this perspective, a number of respondents reported doing everything possible to attract good luck so that they could win. Some attempted to improve their chances of winning by performing some kind of pre-game ritual, like touching, wearing, or using a supposedly lucky object or something with strong magical powers, whereas others, such as Tiziana, felt more confident when using some parts of their body believed to possess magic properties:

I enjoy selecting numbers at random...as when you play...bingo... If my hand is magic, I pick the good ones. [Tiziana, Lotto/SuperEnalotto, age 47].
Some respondents thought that objects resembling one another possessed identical underlying properties. Namely, according to the magical law of similarity, if a thing or an image is like a supposedly lucky thing, it shares the same lucky properties. In the extract hereunder, a gambler describes an unusual ritual that she and her husband carry out before entering the casino at Sanremo, namely, touching a male statue's genitals. ${ }^{15}$ Some winning bets convinced them about the effectiveness of such propitiatory gesture. Indeed, the ritual was sometimes used as a pretext for rationalizing their losses - forgetting to do it meant risking almost certain loss.

On the steps [leading up to the Sanremo casino] stand two statues, one female and the other male. Every time my husband and I pass by the male statue, we usually touch...his genitals [of the statue]...as we think that it brings luck! When we forget to touch the statue and we do not win, he [her husband] says: “That's why we don't win: we didn't touch the statue!" [Greta, Roulette, age 46]

Many interviewees thought they had insider information, they know the system. As reflected in the data, gamblers' feelings of control were often based on using lucky charms, both in games of skill and in games of chance.

Sometimes, I have won using a certain pen that I have at home. One day my pen disappeared... After a few months I've found it...my son had it... So I used it again and I won. [Vittorio, Lotto, age 44]

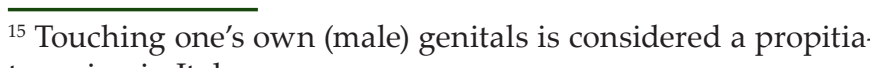
tory sign in Italy. 
Everyone had, to a greater or lesser extent, their propitiatory rites. Mine was kissing a small wooden mask from Africa in my bedroom. Before I went to the racetrack, I kissed my amulet. [Giuseppe, horse race betting, age 44]

Other ex-ante magical rituals mentioned by respondents were developed by personal observation. They consisted in preliminary analysis of some "situational characteristics" of gambling (Griffiths and Wood 2000). These are features of the gambling environment and may be very important variables in any decision to gamble. They include the location of shops, points of sale, or gambling ticket kiosks. Many interviewees often did not gamble just anywhere; their choice was meticulous. As shown by this extract, this gambler likes street corner Lotto booths.

You must play at the corner betting shops...because I've been told that crossroads bring good luck. I've played in various betting shops on street corners and I've always won; when I didn't [play in betting shops on a street corner], I never won. [Vittorio, Lotto, age 44]

Even the looks of people who work at the points of sale or gambling house were believed to be crucial. For some gamblers, it was important that they should not have "the evil eye." This is the "ability" to cause harm to people or things, either intentionally or otherwise, through negative powers, which are cast or directed through a person in the store. Magic here consists in believing that a conscious decision to gamble in an office pool where employees do not have "the evil eye" would increase their chances of winning. As in the following comment to possess sensorial "skill" here is essential.

Before playing, I check that he [the employee who works in the office pool] doesn't have an evil look...as it could bring me bad luck! Many times I just look at him and say to myself: "I will never win here. He brings me bad luck!" [Anna, Totocalcio, age 57]

\section{Conclusion}

\section{You Never Know If It Works...}

The results of this investigation show that superstition, in a variety of forms (signs, magic, conversion), plays a significant role in gambling. This is not to say that interviewees think of themselves as superstitious or define lucky numbers, signs, magic, or conversion as instances of superstition; but it means that if superstition is defined as pointed out in Dundes's work - as a traditional expression "of one or more conditions and one or more results with some of the conditions, signs, and other causes" (1961:28) - then we can say that the respondents did believe in and practiced it.

So, according to my study, people might have a lucky number when betting or a lucky lottery out let, but still not consider themselves to be superstitious. How can this somewhat bizarre attitude be explained? What are the possible reasons for it?

One of the answers to these questions may in clude the meaning of the term superstition. In its wider sense, superstition has come to refer to al of those beliefs and practices that scientific experience identifies as irrational or false, meaningless "relics" of former eras that continue to survive in broad sections of the population. This pejorative acceptation, which is not present in the etymology of the concept, as Benveniste (Belmont 1979) argued, provides us with two different interpretations for the attitudes of the gamblers interviewed.

First of all, they may not consider themselves to be superstitious because, contrary to common meaning of the term, they think their beliefs and practices make sense. Bailey (2007), one of the foremost international scholars on magic and witchcraft of recent years, observed that superstition is any type of action that is not considered effective (by those observing it but also by those putting it into practice) in terms of the expected results. If we accept this conclusion, we then have to hypothesize that the interviewees believe in the effectiveness of their actions or convictions because they do not define themselves as superstitious. Yet, my data appear not to confirm this. As evidenced in the previous pages, a small number of gamblers interviewed would justify their behavior and statements by saying, for example, I really think that rubbing the lottery ticket on a lucky card will make me win. Most would explain their gestures with arguments such as: I never know if it works... In other words, they did not really believe in mistaken causal links and were reluctant to say they believed in superstition; however, they also would not declare that they did not believe in superstition, nor can we say that they do not believe in it at all
So, we can say that these findings are partly in agreement with Campbell's (1996) concept of "half-belief" commonly referred to the fact that people adopt superstition without deeply believing in it. ${ }^{16}$ It is this ambiguous and paradoxical aspect (which mixes belief with disbelief) which, according to Campbell, characterizes superstitions. These are half-beliefs, that is, phenomena in which a lack of faith in the efficacy of a certain practice co-exists with actions which would suggest belief in the self-same practice. Anyway, this dual reticence to admit both a genuine belief in the validity of the superstition and, at the same time, a full commitment to it does not reveal the deep reasons for a behavior that remains bizarre.

A second interpretation that I might give is that the gamblers interviewed do not define themselves as superstitious and they do not define their beliefs and practices as superstitious because they fear being judged by others. In other words, given modern society's negative view of superstition (see Belmont 1979), those who use or practice it may tend to be ashamed of the fact, denying its importance towards others. Future research on this topic is warranted.

\section{Superstition, Uncertainty, "Chance-Skill”} Distinction, and Everyday Life

Although it might be expected that superstition is more pronounced in games of chance, there is no

Nevertheless, when Campbell talks of superstition, he refers to a modern transfiguration of magic, that is, it is the remnants in contemporary society of the ancient beliefs and magic rituals of pre-modern societies, believed to be effective by those 
reason to assume that the belief in and practice of superstition declined with advancing certainty, for example, in games involving skill. Superstition was clearly an accepted part of gambling for most respondents. However, some differences were noted. Dundes's categories of superstition are very useful to investigate connections and relationships between use of superstition and skill-chance distinction. This study shows that autobiographic signs and their conversion have a robust influence on the decision-making of gamblers keen on games of chance (especially those involving numbers). Conversely, the other types of superstition, namely, non-autobiographic signs, their conversion, and magic, cut across both games of chance and games of skill. Although more pronounced in games of chance, magic appeared to be more significant in the experience of interviewees who played skill games. For many respondents, magic consisted in a rite through which individuals thought of "manipulating" the outcome or, more simply, of giving support after placing a bet. For others, magic was instead associated with conversion of non-autobiographic signs, that is, transforming belief into practice

Data confirmed that the majority of respondents subjectively perceived the game they played, whether of chance or of skill, primarily as a game of skill (rather than mainly chance-based or a combination of skill and chance). Thus, superstition created an "illusion of control" (Langer 1975). According to my assumption, gamblers use superstition not because they attribute the outcome to uncontrollable forces, but on the con- trary - because they believe forces are absolutely controllable. This means that most respondents may have overestimated their prospect of success or the probability of a positive outcome. In other words, they believed that they had more skill, knowledge, or ability to predict the outcome of gambling events or influence the game result than they actually had. Sometimes, such skill is useless and not really an advantage per se, as evidenced by many interviewees who attributed excessive ability level to games involving no skill or choice judgment, as Lotto or Roulette; in skill situations, on the contrary, many respondents believed that their skill was excessively influential (see also Ladouceur and Walker 1996). Some respondents considered themselves to be more skilful than others. Very often the elements which may induce an illusion of control are the possibility of choice, familiarity of stimulus and response, and competition. To this effect, it is interesting to observe that a number of studies maintain more generally that escape from common routine in modern society is a reason for gambling (Bloch 1951; Zola 1963). However, one theme running through gamblers' accounts has to do with the relationship between gambling and everyday life. For many respondents, gambling behavior only made sense if closely linked to the events and facts of their ordinary life. So, it was not a way of escaping from the boredom and humdrum of daily life - on the contrary, respondents were constantly looking for signs of their gambling success in everyday life. Conditions involving factors of choice or familiarity stimulated expectancy of success more than objective probability would warrant

\section{How to Predict or Influence the Outcome} of a Game, et cetera..

This research has provided some insights into the world of micro strategies used by respondents to predict or influence the outcome of an event. Some tactics were specific to a particular game, whereas others were not. Among the latter, the most typical include carrying lucky charms, moving away from someone who is supposed to represent a bad omen, playing some "favorite" numbers.

Additionally, data were consistent with a growing body of literature (Friedland 1998; Wohl and Enzle 2002; Wohl, Stewart, and Young 2011), proving that many people believe luck to be an inner quality of the self rather than a random event that happened to befall the self. Interviewees' accounts suggest that illusory perception of control may be attained by transferring supposed personal luck onto an object central to the game through the laws of sympathetic magic.

Results were also consistent with research showing the existence of significant biases, mistaken perceptions, and cognitions (i.e., "gambler's fallacy," "hot outcome") in gambling behavior (Bersabé and Martínez Arias 2000; Ladouceur 2004). Some respondents often attempted to predict what was to occur next based on the history of a previous outcome, even when the underlying process governing those events was independent and static. Contrary to previous research, the above data suggest that superstition is not mere irrationality or a belief/behavior confined to primitive people. Rather, it includes complex and ingenious thinking and rituals with discernible rules and practices. As Henslin (1967) pointed out, such false perception of control over game, although objectively irrational, is logically consistent from the point of view of crapshooters. Basically, they are "rational in their irrationality" (Henslin 1967: 321).

One limitation of this study is the small number of participants. However, being an exploratory study, it was meant to provide an insight into the role of superstition in gambling and to identify the needs for further research, not to draw definitive conclusions or generalized results covering the entire gambling population.

Despite their limitations, the findings suggest two directions for future research; first, a study of the link between superstition and religion. A great number of superstitious gestures are religion-based. For example, Diego Armando Maradona crossed himself every time he left the pitch; other footballers do the same before a penalty shot. Is this just superstition? Or, is it only popular devotion?

Second is an investigation in the role of social networks (family, work colleagues, friends) in fostering and developing superstition-related knowledge. Most gamblers interviewed were not born superstitious, but "became" superstitious through complex processes of transmission, learning, and reproduction of attitudes and behaviors. A comprehensive approach to this topic is needed to promote a deeper understanding of the reasons for the persistence of superstition in modern society. It is hoped that this study will stimulate further work in both areas. 


\section{References}

Aarnio, Kia. 2007. Paranormal, Superstitious, Magical, and Religious Beliefs. PhD Thesis, University of Helsinki, Finland.

Bailey, Michael. 2007. Magic and Superstition in Europe. A Concise History from Antiquity to the Present. Lanham, MD: Rowman \& Littlefield Publishers.

Belmont, Nicole. 1979. “Superstition et religion populaire dans les sociétés occidentales." Pp. 53-70 in La fonction symbolique, edited by M. Izard M. and P. Smith. Paris: Gallimard.

Bersabé, Rosa and Rosario Martínez Arias. 2000. “Superstition in Gambling." Psychology in Spain 4(1):28-34.

Bloch, Herbert A. 1951. “The Sociology of Gambling." American Journal of Sociology 57(3):215-221.

Caillois, Roger. 1961. Man, Play, and Games. New York: Free Press of Glencoe.

Campbell, Colin. 1996. “Half-Belief and the Paradox of Ritual Instrumental Activism: A Theory of Modern Superstition." The British Journal of Sociology 47(1):151-166.

Curtis, Bruce and Cate Wilson. 2001. “Everyday Gambling in New Zealand." Pp. 210-233 in Sociology of Everyday Life in New Zealand, edited by C. Bell. Palmerston North: Dunmore Press Limited.

D’Agati, Marina. 2004. “Gioco d'azzardo e modernità: una prospettiva sociologica." Rassegna Italiana di Sociologia 1(1):79-102.

D’Agati, Marina. 2005. "Credenze fallaci e gioco d'azzardo." Pp. 119-135 in Associazione Italiana di Sociologia, Giovani Sociologi 2004. Milan: Franco Angeli.

Delacroix, Eva and Valérie Guillard. 2008. “Understanding, Defining, and Measuring the Trait of Superstition." Paper presented at the IAREP/SABE World Meeting, September 6, Rome, Italy.

Devereux, Edward. 1968. "Gambling." Pp. 53-62 in International Encyclopedia of the Social Sciences, $6^{\text {th }}$ volume, edited by D. L. Sills. New York: Macmillan \& Free Press.
Dundes, Alan. 1961. “The Structure of Superstition." Midwest Folklore 11(1):25-56.

Frazer, James. 1890. The Golden Bough. London: Macmillan.

Friedland, Nehemia. 1998. "Games of Luck and Games of Chance: The Effect of Luck-versus Chance-orientation on Gambling Decisions." Journal of Behavioral Decision Making 11(3):161-179.

Foster, Kevin and Hanna Kokko. 2009. “The Evolution of Superstitious and Superstition-like Behaviour." Proceedings of the Royal Society B 276(1654):31-37.

Griffiths, Mark and Richard T. A. Wood. 2000. "Risk Factors in Adolescence: The Case of Gambling, Videogame Playing, and the Internet." Journal of Gambling Studies 16(2/3):199-225.

Henslin, James M. 1967. “Craps and Magic." American Journal of Sociology 73(3):316-330.

Hergovich, Andreas, Reinhard Schott, and Martin Arendasy. 2005. "Paranormal Belief and Religiosity." Journal of Parapsychology 69(2):293-303.

Kramer, Thomas and Lauren Block. 2008. "Conscious an Nonconscious Components of Superstitious Beliefs in Judgment and Decision Making." Journal of Consumer Research 34(6):783-793.

Ladouceur, Robert. 2004. "Perceptions Among Pathological and Non-pathological Gamblers." Addictive Behaviors 29(3):555-565.

Ladouceur, Robert and Michael Walker. 1996. “A Cognitive Perspective on Gambling." Pp. 89-120 in Trends in cognitive therapy, edited by P. M. Salkovskis. Oxford: Wiley.

Langer, Ellen J. 1975. "The Illusion of Control." The Journal of Personality and Social Psychology 32(2):311-328.

Lindeman, Marjaana and Kia Aarnio. 2007. "Superstitious, Magical, and Paranormal Beliefs: An Integrative Model." Jour nal of Research in Personality 41(4):731-744.
Malinowski, Bronisław. 1955. Magic, Science, and Religion. New York: Doubleday.

Pihlström, Sami. 2007. “Religion and Pseudo-Religion: An Elusive Boundary." International Journal for Philosophy of Religion 62(1):3-32.

Reith, Gerda. 1999. The Age of Chance: Gambling in Western Culture. London: Routledge.

Stanke, Amanda. 2004. "Religiosity, Locus of Control, and Superstitious Belief." UW-L Journal of Undergraduate Research 7:1-5.

Sundali, James and Rachel Croson. 2006. “Biases in Casino Beting: The Hot Hand and the Gambler's Fallacy." Judgment and Decision Making 1(1):1-12.

Tversky, Amos and Daniel Kahneman. 1971. "The Belief in the Law of Small Numbers." Psychological Bulletin 76(1):105-110.
Weiss, Stephen M., Robert M. Demski, and George J. Backen. 2011. "Fantasy Baseball: A New Way to Gamble or Just Another Game?" Journal of Gambling Issues 26:125-145.

Wohl, Michael and Michael Enzle. 2002. "The Deployment of Personal Luck: Sympathetic Magic and Illusory Control in Games of Pure Chance." Personality and Social Psychology Bulletin 28(10):1388-1397.

Wohl, Michael, Melissa J. Stewart, and Matthew Young. 2011 “Personal Luck Usage Scale (PLUS): Psychometric Validation of a Measure of Gambling-related Belief in Luck as a Personal Possession." International Gambling Studies 11(1):7-21.

Žeželj, Iris et al. 2009. "Construction and Behavioral Validation Of Superstition Scale." Psihologija 42(2):141-158.

Zola, Irving K. 1963. "Observations on Gambling in a Lower-Class Setting." Social Problems 10(4):353-361. 